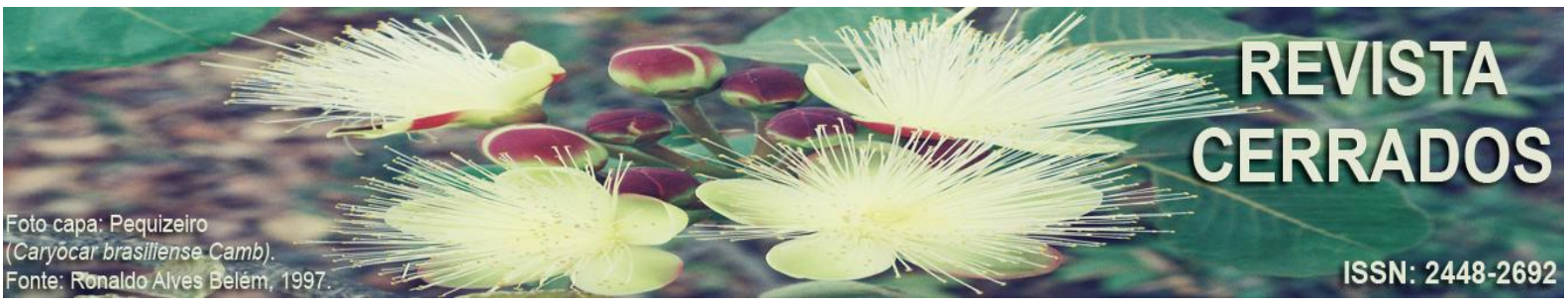

\title{
DETERMINAÇÃO DA EVAPOTRANSPIRAÇÃO REAL DIÁRIA EM ÁREAS IRRIGADAS DO PROJETO JAÍBA (MINAS GERAIS, BRASIL), MEDIANTE IMAGENS LANDSAT 5 - TM
}

\author{
DETERMINATION OF REAL EVAPOTRANSPIRATION DAILY IN \\ AREAS OF JAIBA IRRIGATED PROJECT (MINAS GERAIS, BRAZIL) \\ THROUGH IMAGES LANDSAT 5 - TM
}

\section{DETERMINACIÓN DE LA EVAPOTRANSPIRACIÓN REAL DIARIA EN ÁREAS IRRIGADAS DEL PROYECTO JAÍBA (MINAS GERAIS, BRASIL), MEDIANTE IMAGENES LANDSAT 5 - TM}

\author{
Gabriel Alves Veloso \\ Universidade Federal do Pará - UFPA \\ E-mail<gabrielveloso.geo@gmail.com>. \\ Manuel Eduardo Ferreira \\ Universidade Federal de Goiás - UFG \\ E-mail<mferreira.geo@gmail.com>.
}

Bernardo Barbosa da Silva Universidade Federal de Campina Grande - UFCG

E-mail<bbdasilva.ufpe@gmail.com>.

\section{Resumo}

O presente trabalho teve como objetivo a estimativa da evapotranspiração em áreas irrigadas do projeto Jaíba (MG) e áreas circunvizinhas por meio de dados satelitários. Foram utilizadas cinco imagens do satélite Landsat 5 -TM, órbita 219 ponto 70, do ano de 2011. A estimativa da evapotranspiração real diária foi obtida através do algoritmo SEBAL (Surface Energy Balance Algorithm for Land). O SEBAL é constituído de várias etapas, que consiste na estimativa do balanço de radiação e balanço de energia e evapotranspiração. Para a obtenção desses parâmetros, utilizou-se dados da estação meteorológica localizada na cena Landsat. Foram obtidos valores médios para a evapotranspiração no período de 24 horas de 6,85 mm.dia ${ }^{-1}$, 4,0 mm.dia ${ }^{-1}$, 2,6 mm.dia ${ }^{-1}$, 2,2 mm.dia-1 e 3,4 mm.dia ${ }^{-1}$ para os dias juliano DJ 31, DJ 111, DJ 175, DJ 191 e DJ 255, respectivamente. Observou-se que a evapotranspiração apresentou variação no período analisado devido à quantidade de radiação disponível para cada dia, indicando um comportamento decíduo nas áreas de floresta estacional. A técnica 
utilizada demonstrou-se eficiente nas análises dos componentes estudados, sendo o SEBAL uma ferramenta importante para a gestão ambiental dos recursos hídricos.

Palavras - Chaves: Evapotranspiração; SEBAL; Projeto Jaíba.

\begin{abstract}
This study aimed to estimate evapotranspiration in irrigated areas of Jaíba project (MG) and surrounding areas through satelitários data. Five images of Landsat 5 -TM were used, orbit 219 point 70, 2011. The estimate of daily evapotranspiration was obtained by SEBAL algorithm (Surface Energy Balance Algorithm for Land) .The SEBAL consists of several stages, consisting in estimating the radiation balance and energy balance and evapotranspiration. To obtain these parameters, we used data from the weather station located on the Landsat scene. Mean values for evapotranspiration were obtained within 24 hours of $6.85 \mathrm{~mm}$.dia-1, 4,0 mm.dia-1, 2,6 mm.dia-1, 2,2-1 and $3 \mathrm{~mm}$.dia , $4 \mathrm{~mm}$.dia-1 for Julian days DJ 31, DJ 111, DJ 175, DJ 191 and DJ 255, respectively. It was observed that the evapotranspiration in growth in the period analyzed due to the amount of radiation available for each day, indicating a behavior in the areas of deciduous seasonal forest. The technique used was efficient in the analysis of the components studied, and the SEBAL an important tool for environmental management of water resources.
\end{abstract}

Keywords: Evapotranspiration; SEBAL; Jaíba project.

\title{
Resumen
}

El presente trabajo tuvo como objetivo la estimativa de evapotranspiración en áreas irrigadas del proyecto Jaíba (MG) y áreas circunvecinas por medio de datos satelitarios. Fueron utilizadas cinco imágenes del satélite Landsat 5 - TM, órbita 219 punto 70, del año 2011. La estimativa de la evapotranspiración real diaria fue obtenida a través del algoritmo SEBAL (Surface Energy Balance AlgorithmforLand). SEBAL es constituido de varias etapas, que consiste en la estimativa del balance de radiación e de energía y evapotranspiración. Para la obtención de esos parámetros, se utilizó datos de la estación meteorológica localizada en la escena Landsat. Fueron obtenidos valores medios para la evapotranspiración en el período de 24 horas de 6,85 mm.dia ${ }^{-1}, 4,0 \mathrm{~mm} \cdot \mathrm{dia}^{-1}, 2,6 \mathrm{~mm} \cdot \mathrm{dia}^{-1}, 2,2 \mathrm{~mm} \cdot \mathrm{dia}^{-1}$, y 3,4 mm.dia ${ }^{-1}$ para los días de Juliano DJ 31, DJ 111, DJ 175, DJ 191 y DJ 255, respectivamente. Se observó que la evapotranspiración presentó variación en el período analizado debido a la cantidad de radiación disponible para cada día, indicando un comportamiento caducifolio en las áreas de floresta estacional. La técnica utilizada se mostró eficiente en los análisis de los componentes estudiados, siendo SEBAL una herramienta importante para la gestión ambiental de los recursos hídricos.

Palabras - claves: Evapotranspiración; SEBAL; Proyecto Jaíba. 


\section{INTRODUÇÃO}

A evapotranspiração - ET é uma das principais etapas do ciclo hidrológico. Essa etapa é responsável pela transferência de quase todo o volume de água para a atmosfera, cujo processo conta com a evaporação dos corpos d'água (lagos, oceanos, rios, reservatórios), dos solos e da vegetação úmida, bem como com a transpiração da cobertura vegetal. Compreender os processos envolvidos no armazenamento e liberação de água, seja numa bacia hidrográfica, no solo ou através da vegetação, é de extrema importância para que se tenha um manejo eficaz dos recursos hídricos.

A determinação da evapotranspiração em atividade de irrigação agrícola ganha, a cada dia, mais importância, sobretudo porque as áreas irrigadas, depois do consumo humano, representam a maior parcela de consumo dos recursos hídricos, não apenas no Brasil, mas em todo o mundo. Assim, o conhecimento deste parâmetro, bem como o entendimento de sua variação espacial e temporal, é de grande importância na formulação de modelos de gestão dos recursos hídricos (LIMA et al., 2009).

Nessa perspectiva, o sensoriamento remoto se apresenta como uma técnica eficaz para a identificação de parâmetros terrestres ligados ao clima. Nos últimos 15 anos, alguns métodos foram desenvolvidos e aperfeiçoados para se determinar os componentes do balanço de radiação e energia, com base em imagens orbitais e dados de superfície. Desta forma, é crescente o desenvolvimento de pesquisas para a avaliação dos componentes do balanço de radiação e energia a serem utilizados em modelos de gerenciamento de recursos hídricos.

Neste grupo, o SEBAL (Surface Energy Balance Algorithm for Land) se apresenta como um dos possíveis algoritmos (semi-empíricos) para o cômputo dos componentes do balanço de energia e fluxos da superfície, baseado em dados de estações meteorológicas (in loco) e nos parâmetros espectrais das imagens de satélites (SILVA et al 2005).

O SEBAL foi desenvolvido por Bastiaanssen (1995), consagrado como uma metodologia eficaz na estimativa dos componentes do balanço de radiação, energia e evapotranspiração em várias partes do mundo. Esse algoritmo tem como principal objetivo calcular a evapotranspiração, usando imagens de satélites e alguns dados de superfície de estação meteorológica, tais como velocidade do vento, umidade relativa do ar, temperatura do ar, pressão atmosférica e radiação solar global. 
Diante do exposto, este artigo tem por objetivo estimar a evapotranspiração real diária em áreas irrigadas do projeto Jaíba e áreas circunvizinhas, utilizando imagens do satélite Landsat 5 - TM, mediante aplicação do algoritmo SEBAL, para o ano de 2011.

\section{MATERIAIS E MÉTODOS}

Área de Estudo

A área de estudo está localizada no norte de Minas Gerias, mais especificamente na região conhecida como Mata do Jaíba, nos municípios de Jaíba e Matias Cardoso, margem direita do rio São Francisco e esquerda do Verde Grande, entre as coordenadas

O projeto Jaíba tem como objetivo o desenvolvimento agrícola regional, por meio da construção de uma infraestrutura de lotes agrícolas e a disponibilização de linhas de crédito para os produtores rurais (Figura1). A sua criação resultou na materialização de um polo de produção agrícola, fomentando o crescimento econômico e social da região, com novos sistemas de produção e comercialização (REZENDE, 2002).

Figura 1 - Mapa de localização da área de estudo

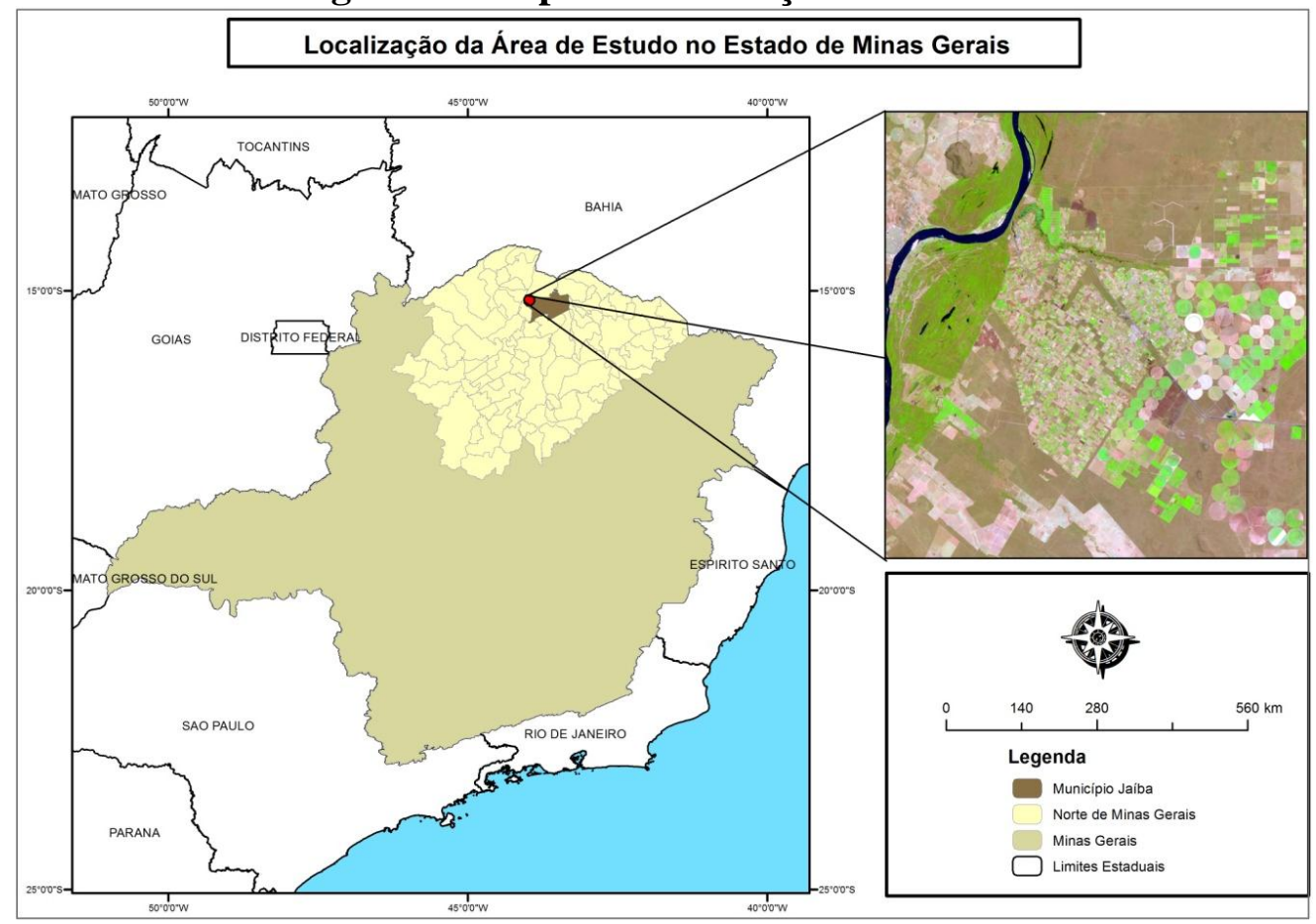

A instalação de projetos de irrigação no norte do semiárido mineiro é uma alternativa de desenvolvimento socioeconômico da região. No entanto, os impactos 
ambientais e econômicos podem ser negativos caso estes projetos não estejam em consonância comum planejamento e gestão dos recursos naturais, sobretudo os recursos hídricos. O perímetro irrigado do Jaíba é um dos mais importantes da região, com uma área total irrigada de $57 \mathrm{mil} \mathrm{ha}$, sendo 26.790 ha na primeira etapa e 30.800 ha na segunda etapa, tendo como meta de expansão atingir 100.000 hectares (MOURA, 2007).

O clima da região é classificado como tropical quente, subtipo semiárido, com período seco igual ou superior a seis meses. $\mathrm{O}$ índice de umidade relativa atinge $60 \%$, sendo os meses mais úmidos dezembro e janeiro, e os mais secos agosto e setembro (PATRUS et al., 2000 apud FREITAS et al., 2008). O regime pluviométrico anual apresenta variações, sendo que os menores índices são inferiores a $800 \mathrm{~mm}$. Freitas et al. (2008), analisando os dados climatológicos da região de 1996 a 2006, apontam uma precipitação média anual de $858,7 \mathrm{~mm}$, concentradas principalmente entre os períodos de novembro e março, com índices mais baixos entre abril e setembro. A temperatura média anual para o mesmo período é de $26,6^{\circ} \mathrm{C}$, sendo junho o mês mais frio, com média de $24,5^{\circ} \mathrm{C}$, e outubro o mês mais quente, com média de $28,9^{\circ} \mathrm{C}$. Segundo o Instituto Brasileiro de Geografia e Estatística (IBGE, 2006), a cobertura vegetal no município de Jaíba é composta principalmente pela Floresta Estacional decidual e semidecidual, típica do clima quente e semiárido, tendo o domínio de vegetação caducifólia (perda das folhas na estação seca) com características xerofíticas, isto é, espécies adaptadas para regiões semiáridas, apresentando estratos de gramíneas, arbustos e árvores, entremeados com cactáceas e bromeliáceas (IBAMA, 2008).

\section{Procedimentos Metodológicos}

Como mencionado, este trabalho visa a estimativa da evapotranspiração real diária em áreas irrigadas do projeto de irrigação Jaíba, com auxílio do satélite Landsat 5 - TM. As imagens TM foram adquiridas no portal de dados do Instituto Nacional de Pesquisas Espaciais (INPE), correspondente à órbita 219 ponto 70, para os dias 31 de janeiro, dia sequencial do ano 31 (DJ31), 21 de abril (DJ111), 24 de junho (DJ175), 10 de julho (DJ191) e 12 de setembro (DJ255), todas do ano de 2011. Estes dias foram escolhidos por não apresentarem cobertura de nuvens na área de estudo, durante a passagem do satélite sobre os municípios Jaíba e Matias Cardoso. 
Uma área na cena de estudo que abrange parte do projeto de irrigação do Jaíba foi definida, já que este está situado na intercessão das órbitas 218 e 219 da imagem Landsat 5. Sabendo-se que os parâmetros meteorológicos e de iluminação mudam de um dia para outro, decidiu-se pesquisar as áreas localizadas na órbita 219 ponto 70, que abrange maior parte do projeto de irrigação.

O processamento digital das imagens de satélite foi executado no software ERDAS, onde as operações matemáticas intra e inter bandas espectrais foram desenvolvidas na ferramenta ModelMaker.

Inicialmente, para a estimativa da evapotranspiração, foram computados os componentes do balanço de radiação na superfície. A figura 2 apresenta as etapas utilizadas na estimativa do balanço de radiação. Detalhes deste procedimento são descritos em Silva et al (2011) e Veloso (2013).

Com a realização destas etapas, foi computado o saldo de radiação $\mathrm{R}_{\mathrm{n}}\left(\mathrm{Wm}^{-2}\right)$ à superfície, utilizando-se a equação (1):

$$
\mathrm{R}_{\mathrm{n}}=\mathrm{R}_{\mathrm{s}}\left(1-\alpha_{\text {sup }}\right)-\mathrm{R}_{\mathrm{e}}+\mathrm{R}_{\mathrm{q}}-\left(1-\varepsilon_{0}\right) \mathrm{R}_{\mathrm{q}}
$$

onde $\mathrm{R}_{\mathrm{s}}$ é a radiação de onda curta incidente; $\alpha_{\text {sup }}$ é o albedo corrigido de cada pixel; $\mathrm{R}_{\mathrm{q}}$ é a radiação de onda longa emitida pela atmosfera na direção de cada pixel; $\mathrm{R}_{\mathrm{e}}$ é a radiação de onda longa emitida por cada pixel; e $\varepsilon_{0}$ é a emissividade de cada pixel.

\section{Figura 2 - Fluxograma do cálculo do saldo de radiação}

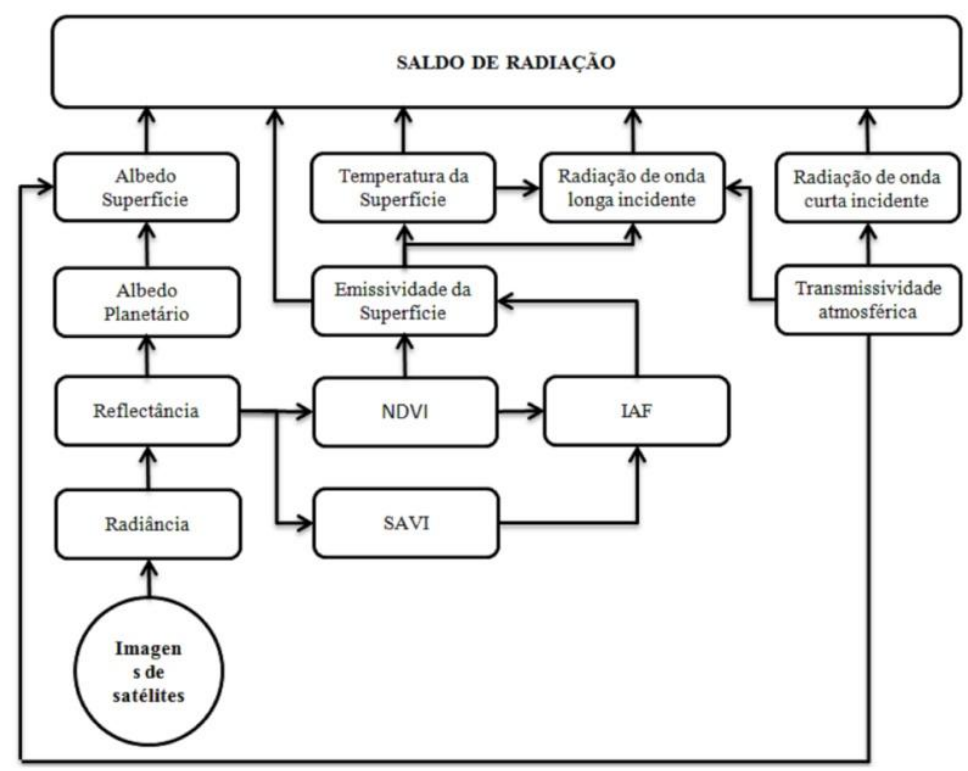


A radiação de onda curta incidente foi calculada utilizando a constante solar, o ângulo zenital, a distância relativa Terra-Sol e a transmissividade atmosférica. Para o cálculo do albedo, foram necessários o albedo no topo da atmosfera, a radiação solar refletida pela atmosfera e a transmissividade atmosférica. Para o cálculo da radiação de onda longa emitida pela atmosfera, utilizou-se a emissividade atmosférica, a constante de Stefan-Boltzmann e a temperatura do ar obtida na estação automática (A539), pertencente ao Instituto Nacional de Meteorologia - INMET, no momento da passagem do satélite. A radiação de onda longa emitida foi calculada a partir da emissividade da banda termal, com intervalo espectral variando de 6 a $14 \mathrm{~nm}$, a constante de Stefan-Boltzmann e a temperatura da superfície.

De posse dos dados do balanço de radiação, foi obtido o fluxo de calor no solo $G$ $\left(\mathrm{Wm}^{-2}\right)$ calculado segundo a equação (2) desenvolvida por Bastiaanssen (2000):

$$
\mathrm{G}=\left[\frac{\mathrm{T}_{\mathrm{s}}}{\alpha}\left(0,0038 \alpha+0.0074 \alpha^{2}\right)\left(1-0,98 \mathrm{NDVI}^{4}\right)\right] \mathrm{Rn}
$$

no qual $\mathrm{T}_{\mathrm{s}}$ é a temperatura da superfície $\left({ }^{\circ} \mathrm{C}\right) ; \alpha$ é o albedo da superfície; NDVI é o índice de vegetação da diferença normalizada; e Rn é o saldo de radiação.

Em seguida, foi calculado o fluxo de calor sensível $\mathrm{H}\left(\mathrm{Wm}^{2}\right)$, etapa do SEBAL mais susceptível a erros, visto que envolve uma série de pressupostos e considerações, sendo necessário o cuidado ao fazê-lo. A estimativa do $\mathrm{H}$ é feita com base na velocidade do vento e na temperatura da superfície, usando uma calibração interna da diferença da temperatura próxima à superfície entre dois níveis da superfície, segundo Bastiaanssen et al. (1998), na equação 3:

$$
H=\rho c_{p} \frac{\left(a+b T_{s}\right)}{r_{a h}}
$$

no qual $\rho$ é a massa específica do ar; $\mathrm{c}_{\mathrm{p}}$ é o calor específico do $\operatorname{ar}\left(1004 \mathrm{Jkg}^{-1} \mathrm{~K}^{-1}\right) ; a$ e $b$ são constantes de calibração da diferença da temperatura entre dois níveis $\mathrm{Z}_{1}$ e $\mathrm{Z}_{2} ; \mathrm{T}_{\mathrm{s}}$ é a temperatura da superfície $\left({ }^{\circ} \mathrm{C}\right)$; e $\mathrm{r}_{\text {ah }}$ é a resistência aerodinâmica ao transporte de calor $\left(\mathrm{sm}^{-1}\right)$. Na estimativa do $\mathrm{H}$ no SEBAL, há a necessidade da escolha de dois pixels na cena, denominados "pixels âncoras", para determinar a variação de temperatura ( $a$ e $b$ ) em dois 
níveis diferentes, bem como a resistência aerodinâmica ao transporte de calor $\left(\mathrm{r}_{\mathrm{hn}}\right)$ em todos os pixels da imagem.

Iniciando o cálculo do $\mathrm{H}$, primeiramente são adquiridos os dados da estação meteorológica no local de estudo, a saber: velocidade do vento $\left(\mathrm{ms}^{-1}\right)$ ao nível de $z \mathrm{~m}$ e a altura média da vegetação (h) em metros, circundante no local da medição da velocidade do vento. As etapas para o cálculo de $\mathrm{H}$ são demonstradas na figura 3.

Com o cálculo de Rn, H e G o fluxo de calor latente (LE) $\left(\mathrm{Wm}^{-2}\right)$ foi calculado como resíduo do balanço de energia pela equação:

$$
\mathrm{LE}=\mathrm{Rn}-\mathrm{G}-\mathrm{H}
$$

no qual LE é o fluxo de calor latente; Rn é o saldo de radiação; G é o fluxo de calor no solo; e H é o fluxo de calor sensível.

Os valores da evapotranspiração real diária - ETc $\left(\mathrm{mm} \mathrm{dia}^{-1}\right)$ foram obtidos a partir de extrapolação do valor instantâneo do LE (Equação 04). Com a estimativa do fluxo de calor latente foi possível determinar a evapotranspiração horária, aplicando a seguinte equação:

$$
\mathrm{ET}_{\mathrm{h}}=3600 \frac{L E}{n}
$$

onde $\mathrm{n}$ representa o calor latente de vaporização da água, que pode ser definido como a energia necessária (em joules) para a evaporar uma massa unitária de água (HARRISON, 1963).

$$
n=[2,501-0,00236(T s-273,16)] 10^{6}
$$

em que $\mathrm{T}_{\mathrm{s}}$ representa a temperatura de superfície $(\mathrm{K})$ em cada pixel.

Seguindo o procedimento metodológico sugerido por Basstiaansen et al. (2005), a evapotranspiração horária foi extrapolada para valores diários, considerando constantes os valores da fração evaporativa, e integrados os valores diários do saldo de radiação, conforme a equação:

$$
\mathrm{ET}_{24 \mathrm{~h}}=86400 \frac{\Delta R n_{24}}{n}
$$

em que $\mathrm{ET}_{24}$ corresponde a evapotranspiração real diária em $\mathrm{mm} \cdot \mathrm{d}^{-1} ; \Delta$ é a fração evaporativa no instante da passagem do satélite; $\mathrm{Rn}_{24}$ representa a radiação de onda curta incidente; e n é o calor latente de vaporização da água. 
Para os valores da fração evaporativa calculados em cada pixel da imagem utilizou-se a seguinte equação:

$$
\Delta=\frac{L E}{R n-G}
$$

Para obter o saldo de radiação 24 horas $\left(\mathrm{Rn}_{24}\right)$ foi aplicada a seguinte equação:

$$
\mathrm{Rn}_{24}=\left(1-\text { albedo) } \mathrm{R}_{\mathrm{s} 24}-123 \tau\right.
$$

albedo de superfície, $\mathrm{R}_{\mathrm{s} \text { 24 }}$ é a média de 24 horas da radiação de onda curta, e $\tau$ a transmitância da atmosfera.

Figura 3 - Fluxograma representativo do processo interativo para obtenção do fluxo de

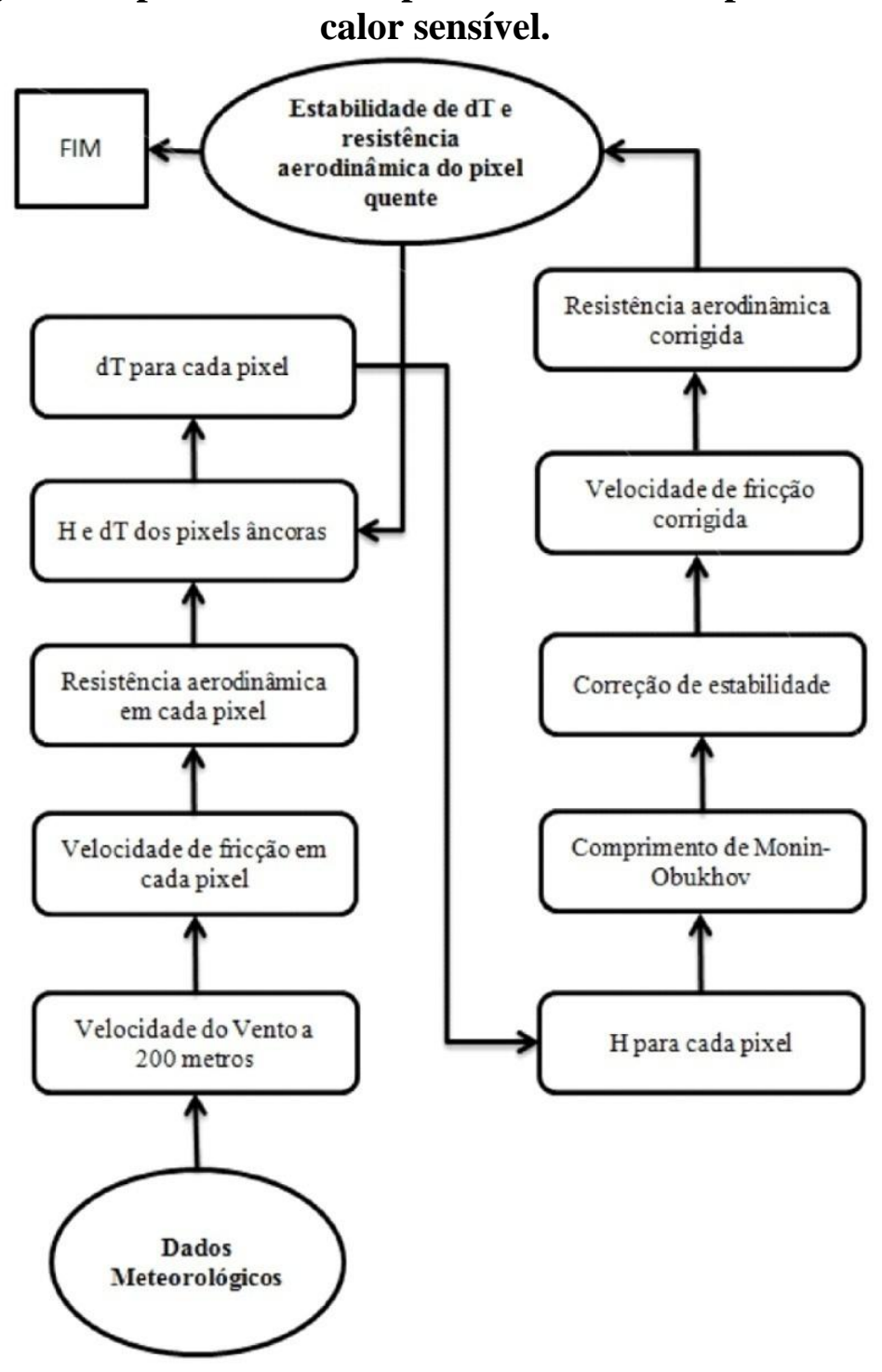




\section{RESULTADOS E DISCUSSÃO}

Numa breve interpretação do uso do solo observado na cena Landsat 5 - TM 219/70 (referente à maior parcela na área de estudo, município de Itacarambi), esta é composta pelas seguintes classes: área urbana, vegetação nativa, agricultura irrigada, água, solo exposto, pastagem e vegetação rala (estas 3 últimas englobadas numa única classe - solo exposto, pastagem e vegetação rala, devido ao elevado grau de confusão espectral entre tais alvos). A figura 4 apresenta esta cena em composição RGB, bandas 4, 3, 5, respectivamente.

Nesta composição de cores, as áreas em vermelho representam extensões com vegetação nativa (Floresta estacional semidecidual), com boa disponibilidade hídrica, localizada nas margens do rio São Francisco e em áreas irrigadas do Projeto Jaíba. Apresentam-se também áreas de vegetação nativa (Floresta estacional decidual), com coloração mais esverdeada. Se diferenciando das áreas irrigadas, a área localizada na região norte da cena faz parte da reserva legal do projeto Jaíba (mata nativa). As áreas com maior exposição de solo podem ser identificadas em tons de azul claro e branco; tais áreas estão espalhadas por diversas partes da área de estudo, e representam solos preparados para cultivo, áreas com vegetação rala e pastagem.

\section{Figura 4 - Área de estudo observada em imagem Landsat 5 - TM, composição 3R 4G} 5B, de 12 de setembro de 2011.

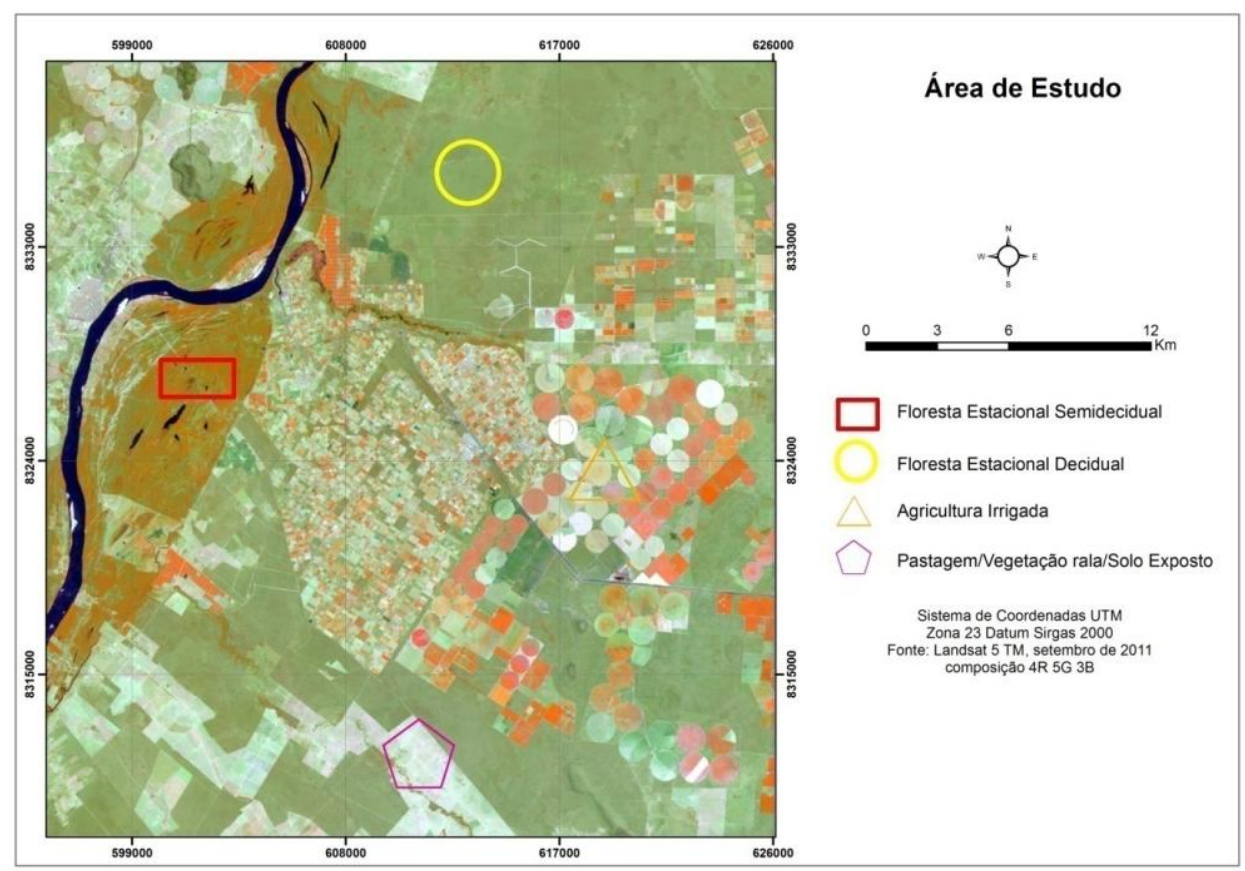


A tabela 1 traz os parâmetros de calibração do algoritmo SEBAL para os dias estudados no ano de 2011, correspondentes à cena Landsat 5 - TM, órbita 219 / ponto 70.

A evapotranspiração está apresentada em valores diários em mm.dia ${ }^{-1}$ para os dias juliano 31 (31 de janeiro), 111 (21 de abril), 175 (24 de junho), 191 (10 de julho) e 255 (12 de setembro), dados estes obtidos inicialmente de forma instantânea no momento da passagem do satélite e, posteriormente, integrados para o período de 24 horas, para todas as cenas desse estudo. Uma das grandes vantagens em se utilizar técnicas de sensoriamento remoto na estimativa da evapotranspiração é a análise da variação espacial desse fenômeno, especialmente em grandes áreas, devido às diferenças dos elementos que compõem a paisagem, bem como em virtude das variações dos componentes climáticos (variação temporal). Dessa forma, a determinação da evapotranspiração, levando-se em consideração sua variação espacial e temporal, vem ganhando cada vez mais importância na gestão dos recursos hídricos, seja de um perímetro irrigado ou de uma bacia hidrográfica.

Tabela 1 - Data das imagens do Landsat 5- TM (Data), Hora local (Hora), ângulo de elevação do sol (E), seno de $Z$, quadrado da distancia terra-sol e seu valor médio (dr), Transmitância atmosférica (Tsw).

\begin{tabular}{cccccc}
\hline Data & Hora & E & senZ & $\mathrm{d}_{\mathrm{r}}$ & Tsw \\
\hline 31/janeiro & $9: 51: 54$ & 56,88 & 0,8375 & 1,0284 & 0,739 \\
21/abril & $9: 51: 58$ & 49,81 & 0,7640 & 0,9890 & 0,722 \\
24/junho & $9: 51: 13$ & 41,01 & 0,6563 & 0,9673 & 0,719 \\
10/julho & $9: 51: 08$ & 41,33 & 0,6605 & 0,9674 & 0,721 \\
12/setembro & $9: 50: 54$ & 54,35 & 0,8126 & 0,9895 & 0,762 \\
\hline
\end{tabular}

Fonte: autores

Os dados complementares às imagens do Landsat 5 - TM, utilizados no balanço de radiação, balanço de energia e estimativa da evapotranspiração com o SEBAL, estão descritos na tabela 2. Observa-se que nos dias com baixa nebulosidade, a temperatura do ar variou entre 13,7 a $34,5{ }^{\circ} \mathrm{C}$, enquanto a umidade relativa do ar variou em 16 a $95 \%$. A velocidade média do vento apresentou variação em 0,67 a $2,32 \mathrm{~m} \mathrm{~s}^{-1}$; já a pressão atmosférica 
apresentou estabilidade, com variação de 96,04 a 96,75 KPa. A radiação solar global diária manteve-se entre 14,68 a $30,45 \mathrm{MJ} \mathrm{m}^{-2}$.

Na figura 5 são apresentados os mapas da evapotranspiração para os dias analisados, onde se apresentam classes com magnitude de 0 a $8 \mathrm{~mm} \mathrm{dia}^{-1}$ nas áreas irrigadas do projeto Jaíba e áreas circunvizinhas. A evapotranspiração referente ao dia 31, os valores de 0 a 2 mm.dia ${ }^{-1}$ (em vermelha) correspondem à vegetação rala e solo exposto; os valores de 2 a $4 \mathrm{~mm} \cdot \mathrm{dia}^{-1}$ (em marrom) correspondem à áreas com presença de pasto e culturas em estágio inicial de desenvolvimento; o intervalo de 4 a 7 mm.dia ${ }^{-1}$ engloba as áreas de cultivo irrigado, como também áreas com vegetação arbustiva e pastagem perene (em amarela e verde claro). Nota-se que áreas irrigadas, em sua maioria, apresentam valores menores que as áreas de vegetação nativa (de acordo com o descrito pela literatura).

Tabela 2 - Dados da estação meteorológica e dados complementares do SEBAL, incluindo Temperatura do ar máxima e mínima diárias $\left({ }^{\circ} \mathrm{C}\right)$, Umidade relativa máxima e mínima (\%), velocidade média do vento $\left(\mathrm{vv} \mathrm{m} \mathrm{s}^{-1}\right)$ a 2 metros, pressão atmosférica média diária ( $\left.p_{0}, \mathrm{KPa}\right)$, radiação solar global diária $\left(\mathrm{R}_{\mathrm{s}} 24, \mathrm{MJ}^{-2}\right)$ e radiação solar diária no topo da atmosférica ( $R s T O A, \mathrm{MJ} \mathrm{m}^{-2}$ )

\begin{tabular}{lllllllll}
\hline DJ & Tmax & Tmin & URmax & URmin & $\mathbf{V V}$ & $\mathbf{p}_{\mathbf{0}}$ & $\mathbf{R}_{\text {s24 }}$ & RsTOA \\
\hline 31 & 33,6 & 19 & 95 & 25 & 0,67 & 96,04 & 30,45 & 40,60 \\
111 & 31,8 & 18,8 & 89 & 41 & 1,5 & 96,15 & 21,54 & 31,88 \\
175 & 29,7 & 14,1 & 86 & 33 & 2,32 & 96,34 & 18,57 & 26,17 \\
191 & 29,1 & 13,7 & 94 & 28 & 2,17 & 96,75 & 14.68 & 26,74 \\
255 & 34,5 & 14,5 & 85 & 16 & 2,7 & 96,45 & 22,34 & 34,81 \\
\hline
\end{tabular}

Fonte: INMET e autores

As áreas com os valores mais elevados, de 7 a 8 mm.dia ${ }^{-1}$ (em verde escuro), predominam as classes de floresta estacional decidual, semidecidual e algumas áreas de cultivo irrigado. Essa predominância dos valores mais elevados está associado aos meses janeiro a abril, correspondente à estação chuvosa, na qual a vegetação está em pleno desenvolvimento, apresentando valores de NDVI, em sua maioria, na ordem de 0,58 a 0,87 (i.e., elevada atividade fotossintética). Nessa mesma data há uma maior disponibilidade de radiação solar incidente, como observado na tabela 2 , apresentando valor de $30,45 \mathrm{MJ} \mathrm{m}^{-2}$, sendo esse o maior valor entre os dias estudados, impactando no valor de saldo de radiação na ordem de $800 \mathrm{Wm}^{-2}$, bem como nos valores de albedo de superfície, de 9 a $13 \%$. 
Observa-se que os valores elevados de evapotranspiração estão diretamente relacionados à estação do ano, bem como à quantidade de energia disponível para este processo. Esse fato torna-se mais evidente quando são analisados os mapas nos dias seguintes ao DJ 31, com uma diminuição gradual nos valores de evapotranspiração nos dias 111, 175 e 191, voltando a apresentar aumento no dia 255 (Tabela 3). Essa diminuição dos valores da evapotranspiração está associado à sazonalidade do clima local, marcada pela mudança no regime hídrico entre a estação chuvosa e a seca, bem como pela diminuição da radiação solar incidente verificada nos dias 111, 175 e 191, também ampliada no dia 255. Esse fato foi constatado pelos dados da estação meteorológica localizada no interior da área de estudo (Tabela 2), e com os dados apresentados na tabela 3 e figura 5 (dias 175 e 191), isto é, com os menores valores médios de evapotranspiração no período analisado, condição relacionada à estação climática (período de estiagem), provocando mudanças na vegetação nativa, sobretudo nas áreas de floresta estacional decidual (com perda de folhas durante esse período, diminuindo o processo de evapotranspiração).

\section{Figura 5 - Mapa de Evapotranspiração real diária (mm.dia-1) para os dias analisados.}

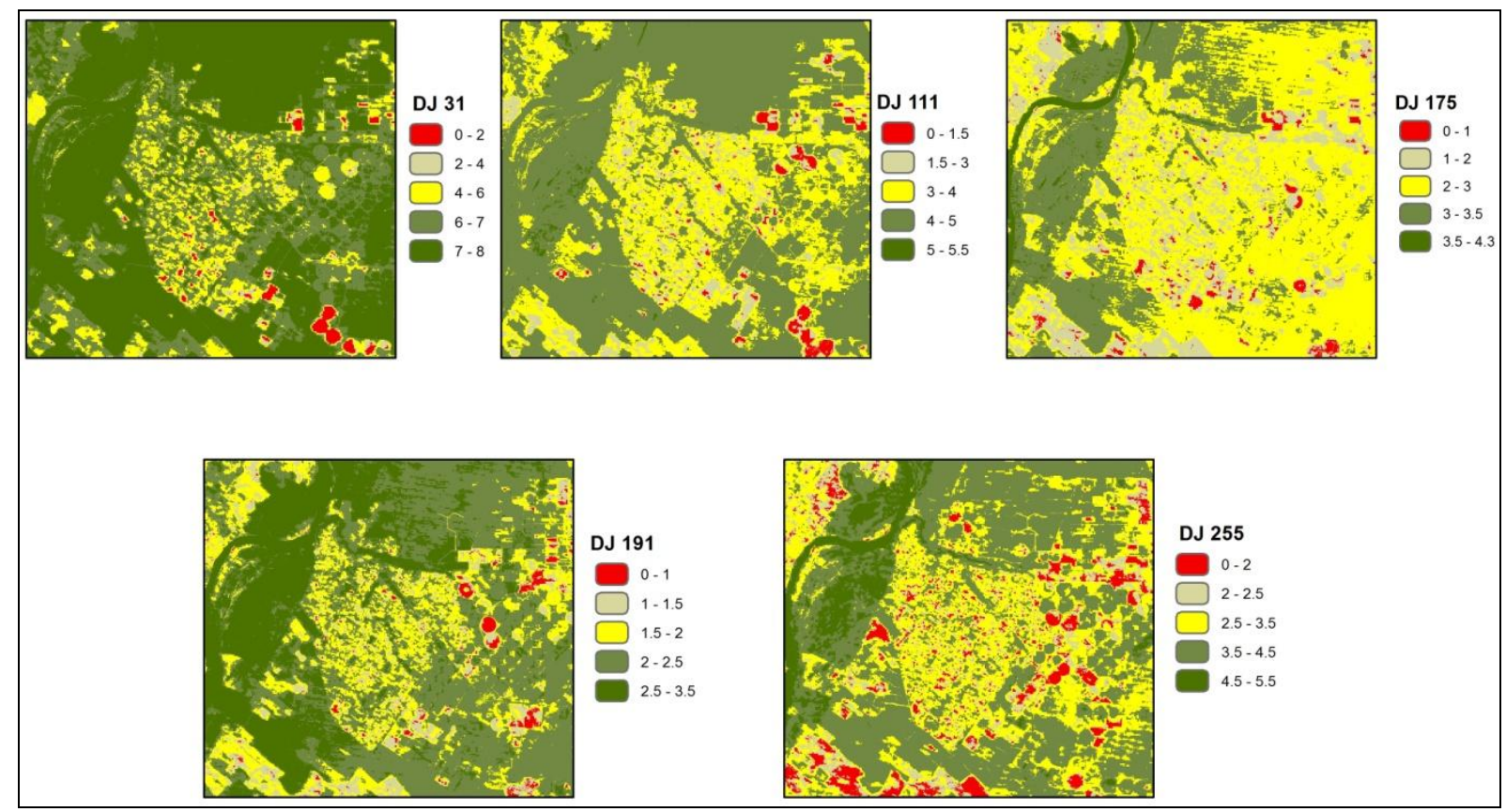

Outro fator importante para esses dias (175 e 191) é a quantidade de radiação solar global disponível, apresentando valores na ordem de $18,57 \mathrm{MJ} \mathrm{m}^{-2} \mathrm{e} 14,68 \mathrm{MJ} \mathrm{m}^{-2}$, 
respectivamente, demonstrando uma diminuição dos valores registrados nos dias 31 e 111. No dia 255 há um aumento nos valores da evapotranspiração em relação aos dias anteriores; esse fato está associado a uma maior incidência de radiação solar global, devido à mudança na estação do ano, neste caso, início da primavera.

Tabela 3 -Valores estatísticos de Evapotranspiração para os dias estudados.

\begin{tabular}{ccccc}
\hline DJ & Mínimo & Máximo & Média & Desvio Padrão \\
\hline 31 & 0,1 & 8 & 6,85 & 1,1 \\
111 & 0,01 & 5,7 & 4,0 & 0,7 \\
175 & 0,003 & 4,4 & 2,6 & 0,6 \\
191 & 0,003 & 3,5 & 2,2 & 0,4 \\
255 & 0,01 & 5,9 & 3,4 & 0,8 \\
\hline
\end{tabular}

Fonte: autores

Para uma melhor análise do comportamento da evapotranspiração no período estudado, foram selecionadas as áreas com floresta estacional decidual, floresta estacional semidecidual, agricultura irrigada e solo exposto, pastagem e vegetação rala para uma avaliação mais detalhada. A tabela 4 apresenta os parâmetros estatísticos mínimo, máximo, médio e desvio padrão para as áreas selecionadas.

Observando-se os valores dessas classes de uso do solo, notam-se valores baixos de desvio padrão para as cenas avaliadas nesta pesquisa. As áreas de floresta estacional decidual e semidecidual tiveram variação semelhante de evapotranspiração no período analisado, apresentando variação nos valores médios, em torno de 2,40 mm.dia ${ }^{-1}$ a 7,50 mm.dia ${ }^{-1}$, nos dias 191 e 31, respectivamente. Gomes (2009) encontrou valores de evapotranspiração no bioma Cerrado - bacia hidrográfica do rio Mogi-Guaçu, na região de Santa Rita do Passa Quatro - São Paulo, superiores a 7 mm.dia ${ }^{-1}$. Bezerra (2006), em estudo da evapotranspiração na região do Cariri Cearense, em áreas da Chapada do Araripe, encontrou valores na ordem de $4 \mathrm{~mm} \cdot \operatorname{dia}^{-1}$ a $6 \mathrm{~mm} \cdot \mathrm{dia}^{-1}$. Nota-se que as áreas de vegetação natural apresentaram instabilidade sazonal durante o período estudado, sendo esse fato ligado à sazonalidade climática da região.

A área de cultivo irrigado apresentou valores de evapotranspiração inferiores às áreas de vegetação nativa, com variação de $1,94 \mathrm{~mm} \cdot \mathrm{dia}^{-1}$ a $6,70 \mathrm{~mm} \cdot \mathrm{dia}^{-1}$ no período 
estudado. Essa oscilação nos valores de evapotranspiração pode ser explicada pela quantidade de energia disponível para o processo evaporativo, bem como pela dinâmica de uso do solo em áreas irrigadas. Trezza (2006) obteve valores de evapotranspiração na ordem 0,001 mm.dia ${ }^{-1}$ a 8,20 mm.dia ${ }^{-1}$ em áreas agrícolas que abrangem o reservatório do Rio Guárico, na Venezuela, sendo que as áreas onde o arroz é o principal cultivo apresentaram média de 4,43 mm.dia ${ }^{-1}$. Já Bastiaanssen e Badara (2001), em estudo da evapotranspiração pelo método SEBAL, obtiveram valores de 2,9 mm.dia ${ }^{-1}$, 4,9 mm.dia ${ }^{-1}$ e 5,6 mm.dia ${ }^{-1}$ em áreas agrícolas próximas ao reservatório de Kirimdi Oya, Sri Lanka, nos dias 19/06/1995, 08/08/1996 e 16/02/1997, respectivamente.

Por sua vez, as áreas de solo exposto, pastagem e vegetação rala apresentaram os menores valores de evapotranspiração, sendo de $1,08 \mathrm{~mm} \cdot \mathrm{dia}^{-1}$ a $6,68 \mathrm{~mm} \cdot \mathrm{dia}^{-1}$, nos dias 191 e 31, respectivamente. Nota-se um padrão nos maiores e menores valores de evapotranspiração no período de estudo, sendo esses relacionados com à sazonalidade climática e à quantidade de radiação solar global.

Tabela 4 - Resumo estatístico dos valores de Evapotranspiração das classes de uso do solo.

\begin{tabular}{|c|c|c|c|c|c|}
\hline DJ & $\begin{array}{l}\text { Parâmet } \\
\text { ros }\end{array}$ & FED & FESD & Área Irrigada & $\begin{array}{l}\text { Solo exposto/ } \\
\text { Pastagem } \\
\text { /Vegetação rala }\end{array}$ \\
\hline \multirow{4}{*}{31} & Mínimo & 7,48 & 7,37 & 6,70 & 4,38 \\
\hline & Máximo & 7,84 & 7,80 & 7,10 & 6,68 \\
\hline & Médio & 7,68 & 7,61 & 6,87 & 5,62 \\
\hline & $\begin{array}{l}\text { Desv. } \\
\text { Padrão }\end{array}$ & 0,06 & 0,07 & 0,08 & 0,44 \\
\hline \multirow{4}{*}{111} & Mínimo & 4,35 & 4,36 & 3,74 & 2,45 \\
\hline & Máximo & 4,75 & 4,82 & 4,12 & 3,77 \\
\hline & Médio & 4,54 & 4,60 & 3,88 & 3,15 \\
\hline & $\begin{array}{c}\text { Desv. } \\
\text { Padrão }\end{array}$ & 0,08 & 0,10 & 0,08 & 0,21 \\
\hline \multirow{4}{*}{175} & Mínimo & 2,78 & 3,17 & 2,40 & 1,10 \\
\hline & Máximo & 3,21 & 3,50 & 2,97 & 1,92 \\
\hline & Médio & 2,99 & 3,33 & 2,79 & 1,50 \\
\hline & $\begin{array}{c}\text { Desv. } \\
\text { Padrão }\end{array}$ & 0,08 & 0,07 & 0,11 & 0,14 \\
\hline \multirow{4}{*}{191} & Mínimo & 2,31 & 2,57 & 1,94 & 1,08 \\
\hline & Máximo & 2,61 & 2,85 & 2,36 & 1,69 \\
\hline & Médio & 2,45 & 2,74 & 2,23 & 1,42 \\
\hline & $\begin{array}{l}\text { Desv. } \\
\text { Padrão }\end{array}$ & 0,05 & 0,03 & 0,07 & 0,09 \\
\hline \multirow{4}{*}{255} & Mínimo & 3,40 & 4,36 & 3,23 & 1,02 \\
\hline & Máximo & 3,95 & 4,86 & 4,05 & 2,24 \\
\hline & Médio & 3,71 & 4,66 & 3,72 & 1,66 \\
\hline & $\begin{array}{l}\text { Desv. } \\
\text { Padrão }\end{array}$ & 0,10 & 0,09 & 0,14 & 0,21 \\
\hline
\end{tabular}

Fonte: autores 
Nas figuras 6, 7 e 8 estão representada os valores de 15 pixels, os quais ilustra o processo de repartição do saldo de radiação - Rn pelos componentes do balanço de energia (Fluxo de calor Latente - LE, Fluxo de calor sensível - H e Fluxo de calor no solo - G) obtidos em áreas de recordes de floresta estacional decidual, áreas de agricultura irrigada e áreas da classe de solo exposto/pastagem/vegetação rala respectivamente para os dias estudados. Os gráficos A, B, C, D e E correspondem aos dias juliano 31 (31 de janeiro), 111 (21 de abril), 175 (24 de junho), 191 (10 de julho) e 255 (12 de setembro) respectivamente. Observa-se na figura 6 correspondente a área de floresta estacional decidual, que o saldo de radiação $(\mathrm{Rn})$ apresentou variação entre 600 a $700 \mathrm{Wm}^{-2}$, onde á uma predominância do consumo dessa energia pelo fluxo de calor latente - LE. O fluxo de calor latente (LE) corresponde à quantidade de energia que é utilizada nos processos de evapotranspiração e na transpiração dos vegetais. Segundo Bastiaanseen et al. (1998), o LE liberado no processo de evapotranspiração é de suma importância para vários processos atmosféricos, uma vez que a intensificação ou dissipação de um sistema depende da disponibilidade de LE na região em que o mesmo se desenvolve.

No dia 31 (gráfica A) a energia utilizada pelo LE corresponde a aproximadamente a $91 \%$ do $\mathrm{Rn}$. Esse resultado está associado à dinâmica que o regime chuvoso provoca na vegetação, pois a vegetação verde tem alta absorção da radiação eletromagnética. Observa-se que o consumo da energia do Rn pelo LE vai diminuindo no decorrer do ano, chegando a aproximadamente $60 \%$ no dia 255 (gráfico E). Este resultado está associado a deciduidade da vegetação e a quantidade de radiação disponível para o processo evaporativo.

As áreas de agricultura irrigada (Figura 7) apresentou comportamento semelhante as áreas de floresta estacional decidual, no qual á uma predominância do consumo da energia do Rn pelo LE. Entretanto, a área de cultivo irrigado demonstrou mais estabilidade na variação do consumo do LE no decorrer do ano, apresentando variação de consumo de $88 \%$ do Rn para o dia 31 (gráfico A) e de 75\% no dia 255 (gráfico E). Este resultado está associado a disponibilidade hídrica dessas áreas no período de estiagem pelo sistema de irrigação. 
VELOSO, G. A.; FERREIRA, M. E.; SILVA, B. B.

Determinação da evapotranspiração real diária em áreas irrigadas do projeto Jaíba (Minas Gerais, Brasil), mediante imagens Landsat 5 - TM

\section{Figura 6 - Divisão dos Componentes do Balanço de Energia na Floresta Estacional Decidual}
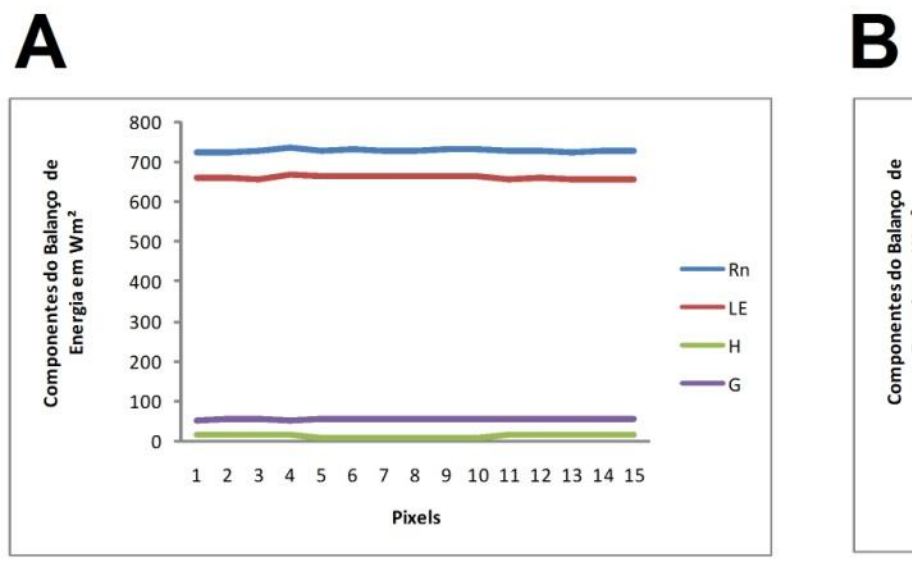

C
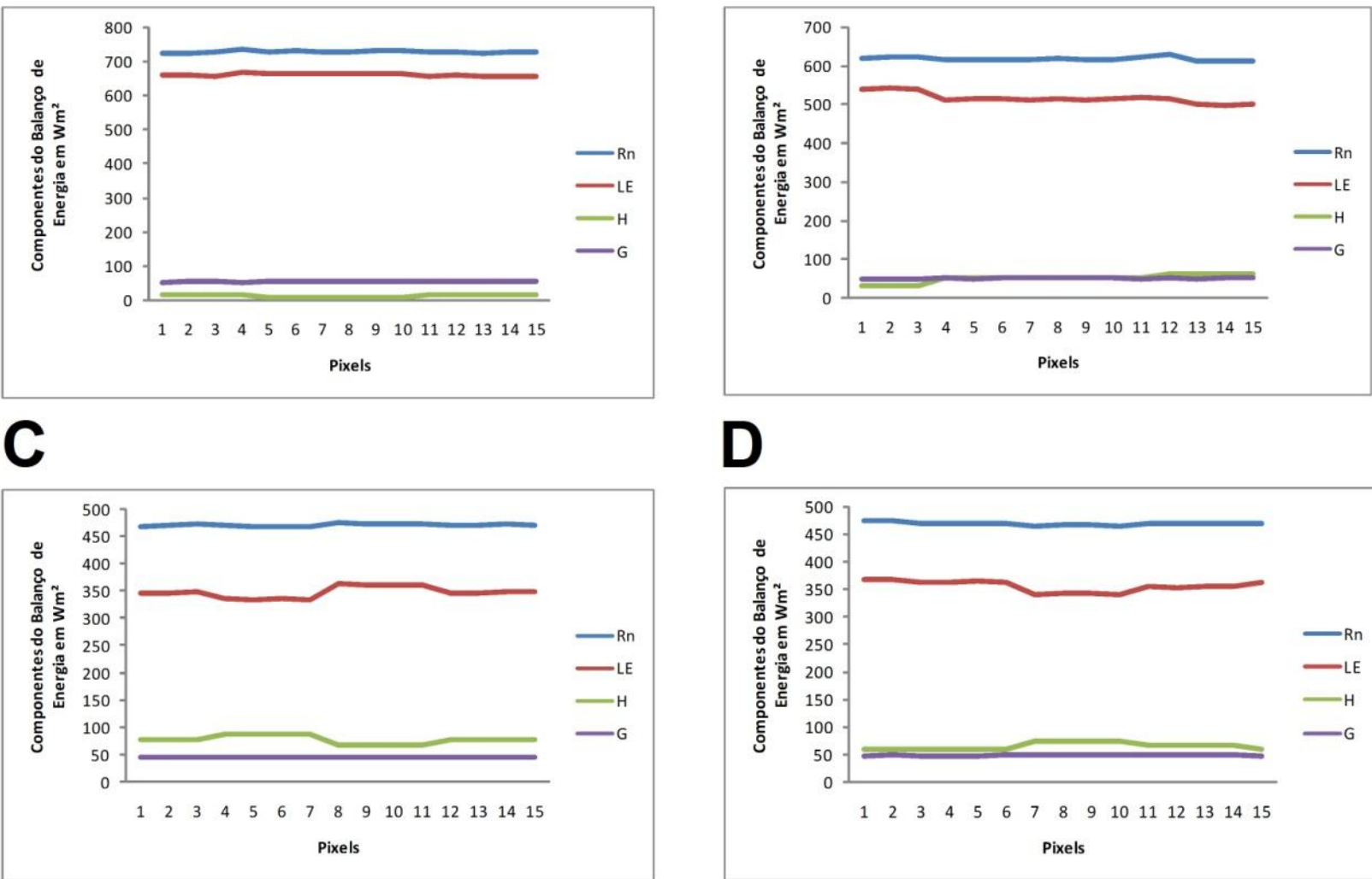

D

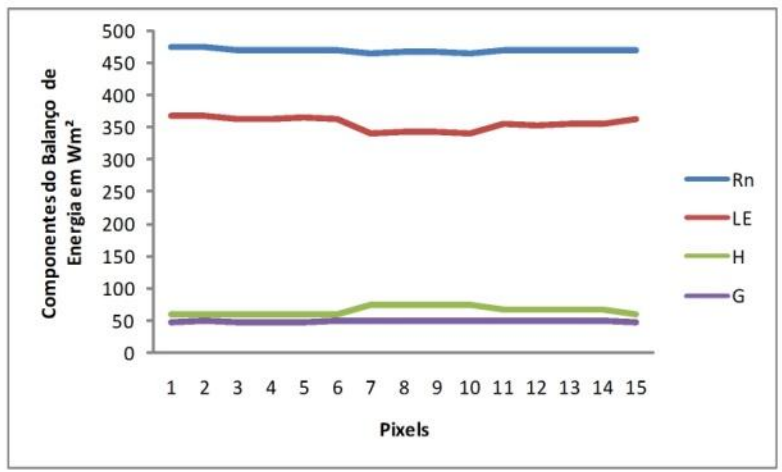

E

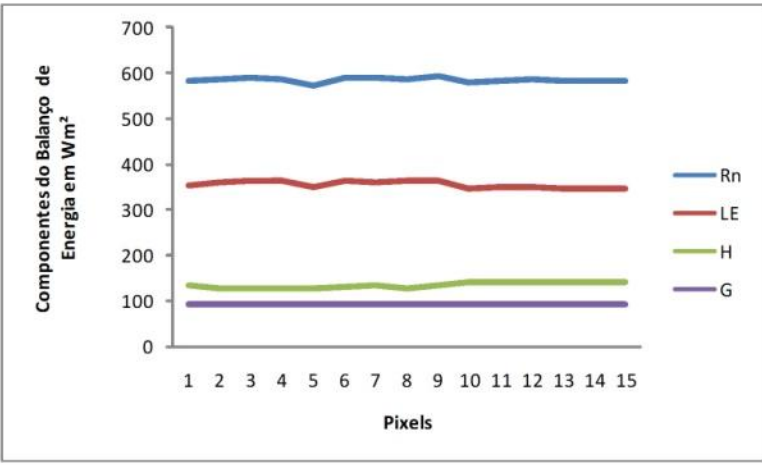


VELOSO, G. A.; FERREIRA, M. E.; SILVA, B. B.

Determinação da evapotranspiração real diária em áreas irrigadas do projeto Jaíba (Minas Gerais, Brasil), mediante imagens Landsat 5 - TM

Figura 7 - Divisão dos Componentes do Balanço de Energia em Áreas de Cultivo

A Irrigado

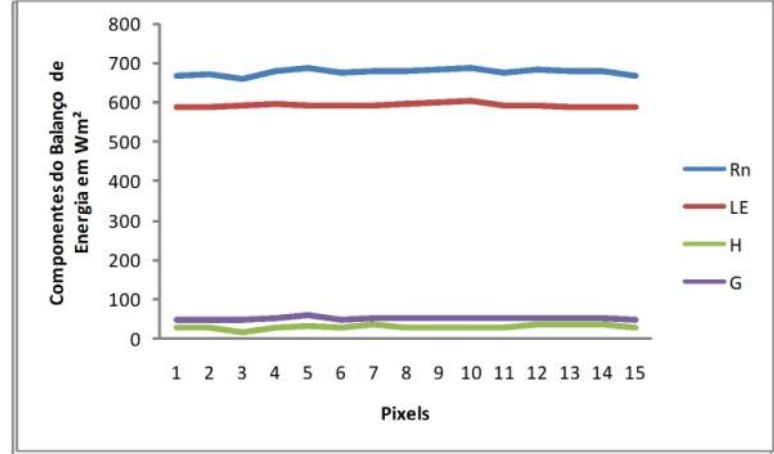

B

C
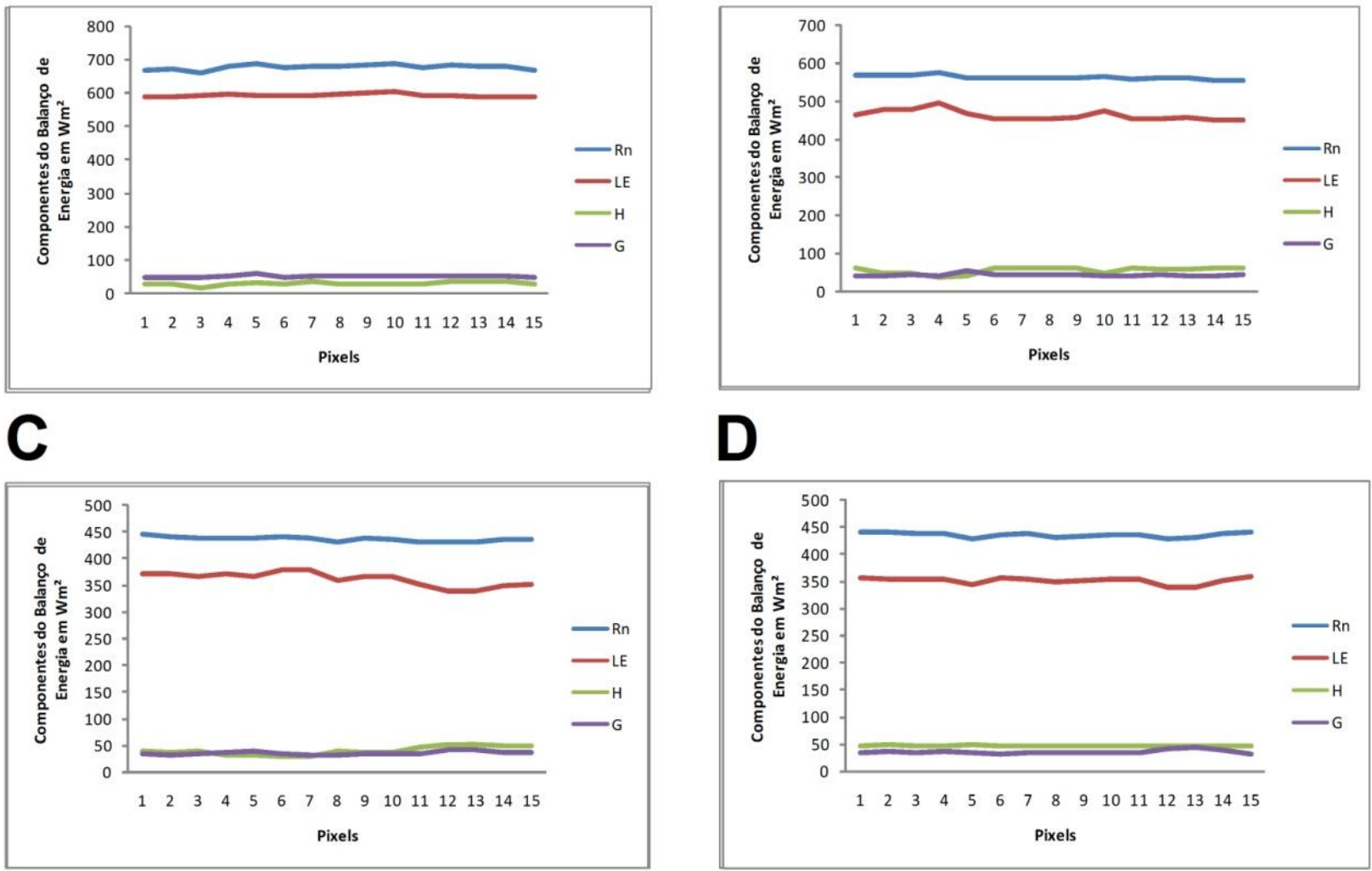

D

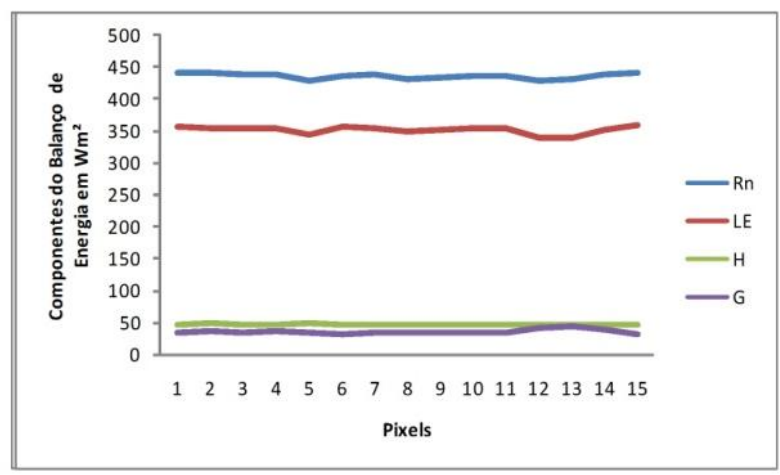

$\mathbf{E}$

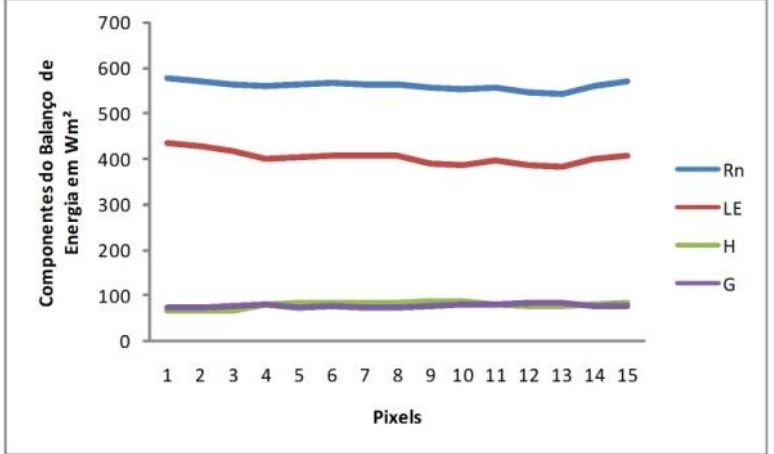


Figura 8 - Divisão dos Componentes do Balanço de Energia em Áreas de Solo Exposto e Pastagem

A

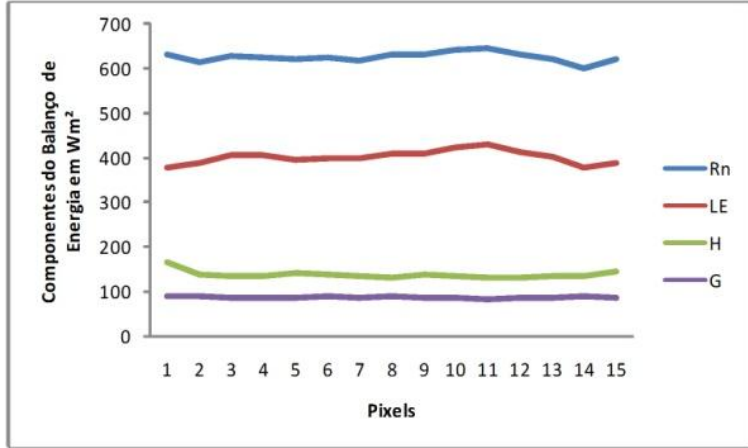

C

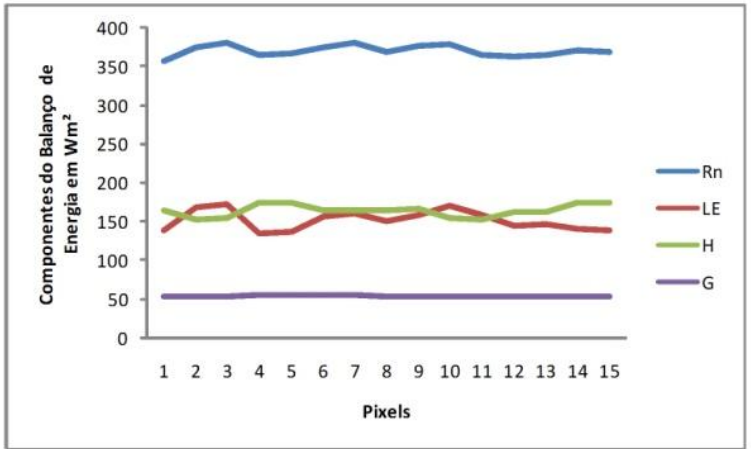

$\mathbf{E}$

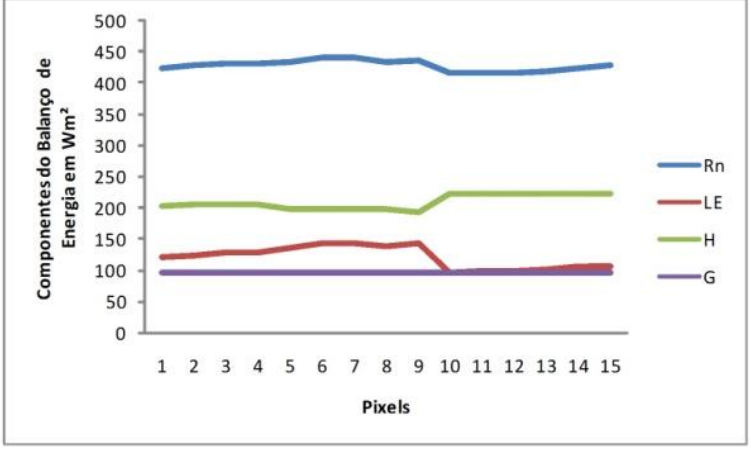

B

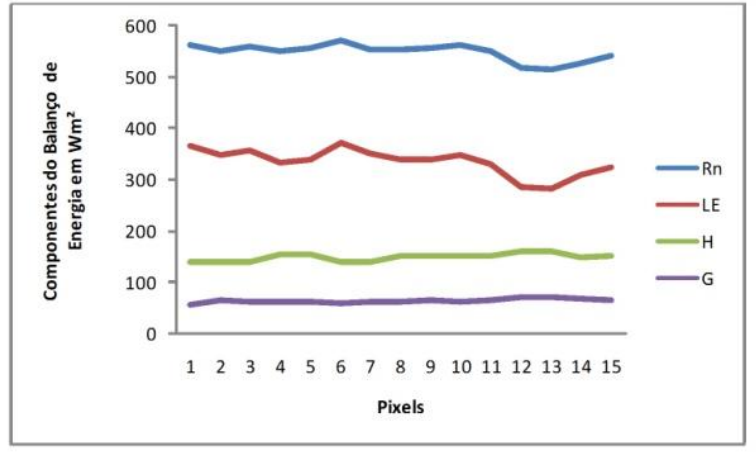

D

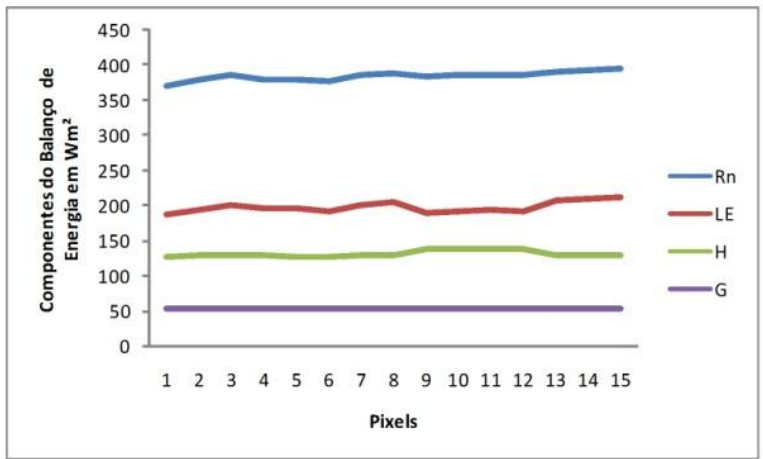

A área da classe de solo exposto/pastagem/vegetação rala (Figura 8) foi a que apresentou maior instabilidade. No período chuvoso que corresponde aos dias 31 e 111 (gráficos A e B respectivamente) á predominância do consumo do $\mathrm{Rn}$ pelo LE em aproximadamente $60 \%$. Esse resultado é explicado pela influência do regime hídrico sobre as áreas de pastagem e vegetação rala. No entanto, no decorrer do período analisado, percebe-se uma diminuição da energia utilizada para o processo de evaporação e transpiração das plantas 
(LE) e o aumento do fluxo de calor sensível $(\mathrm{H})$, sendo padrão associado à dinâmica que a estação chuvosa imprime à vegetação e na pastagem. O fluxo de calor sensível $(\mathrm{H})$ corresponde à troca de calor entre a superfície e as camadas da atmosfera nas suas proximidades. Essas trocas de calor ocorrem, sobretudo por convecção, devido às diferenças de temperatura entre a superfície e as camadas da atmosfera. Dessa forma, no dia 255 (gráfico E) á um maior consumo do $\mathrm{Rn}$ pelo $\mathrm{H}$, no qual essa energia está sendo empregada para aquecimento do ar.

O fluxo de calor no solo $(\mathrm{G})$ apresentou-se estável no período analisado consumindo em média $10 \%$ do Rn. Este representa o transporte vertical de calor através dos processos de condução, onde o calor é transmitindo das camadas mais superficiais para as camadas mais profundas no período diurno, e no sentido inverso no período noturno. A inversão do fluxo de calor no solo dá-se em função da temperatura da superfície da terra e do interior do solo de um período para o outro. Como as camadas superficiais do solo recebem mais energia durante o período diurno, devido à incidência da radiação solar, o fluxo de calor por condução será das camadas mais superficiais para as mais profundas. No período noturno, quando a radiação solar cessa, as camadas superficiais começam a esfriar paulatinamente e as camadas mais profundas passam a ficar mais aquecidas, invertendo o fluxo de calor no solo das camadas mais profundas para as camadas superficiais. Os fluxos de calor no solo são fortemente dependentes das condições climáticas e também das condições da superfície (BEZERRA, 2006).

\section{CONSIDERAÇÕES FINAIS}

A estimativa da evapotranspiração no perímetro irrigado do Jaíba e áreas circunvizinhas, com o uso das imagens do satélite Landsat 5 - TM e o algoritmo SEBAL, apresentaram uma boa correlação com os dados de literatura. A técnica possibilita identificar padrões que diferenciam áreas irrigadas das não irrigadas (ou áreas antropizadas daquelas com vegetação nativa), bem como indica as diferenças nos elementos do balanço de radiação, balanço de energia e evapotranspiração no interior da cena de estudo, possibilitando uma maior compreensão da variação espacial e temporal desses elementos. 
A evapotranspiração real diária (24 horas) apresentou variação de 0 a $8 \mathrm{~mm}_{\text {dia }}{ }^{-1}$ nas áreas irrigadas do projeto Jaíba e áreas circunvizinhas. Em fato, as áreas de cultivo irrigado apresentaram valores inferiores das áreas de vegetação nativa, com variação na ordem de 1,94 a 6,70 mm.dia ${ }^{-1}$ no período estudado. Esta variação pode ser explicada pela quantidade de energia disponível para o processo evaporativo, bem como pela dinâmica de uso do solo das áreas irrigadas. As áreas de solo exposto, pastagem e vegetação rala apresentaram os menores valores de evapotranspiração nos dias estudados. Também observou-se nesta pesquisa um padrão entre os maiores e menores valores de Evapotranspiração, sendo estes relacionados com a sazonalidade climática da região.

Por fim, fica evidente a importância do sensoriamento remoto e do algoritmo SEBAL para o estudo da variabilidade dos componentes do balanço de radiação, energia e evapotranspiração em escala regional, sobretudo em áreas áridas e semiáridas, auxiliando na tomada de decisão para um uso dos recursos hídricos de forma mais eficiente.

\section{AGRADECIMENTOS}

À CAPES, pela concessão de uma bolsa de estudos de doutorado ao primeiro autor. Ao CNPq, pela bolsa de Produtividade em Pesquisa concedida ao segundo e ao terceiro autores.

\section{REFERÊNCIAS}

BASTIAANSSEN, W. G. M. SEBAL - Based Sensible and Latent Heat Fluxes in the Irrigated Gediz Basin. Turkey. Journal of Hydrology, v. 229, p.87-100, 2000.

BASTIAANSSEN, W.G.M.; BANDARA, K.M.P.S. Evaporative depletion assessments for irrigated watersheds in Sri Lanka. Irrigation Science, v. 21, p. 1- 15, 2001.

BASTIAANSSEN, W. G. M. Regionalization of surface flux densities and moisture indicators in composite terrain. Ph.D. Thesis, Wageningen Agricultural University, Wageningen, Netherlands, 1995. 237p.

BASTIAANSSEN, W. G. M. Regionalization of surface flux densities and moisture indicators in composite terrain: A remote sensing approach under clear skies in Mediterranean climate. PhD. Dis., CIP Data Koninklijke Biblioteheek, Den Haag, the Netherlands, 1998. 272 . 
BEZERRA, B. G. Balanço de energia e evapotranspiração em áreas com diferentes tipos de cobertura de solo no cariri cearense através do algoritmo SEBAL. Dissertação de Mestrado em Meteorologia. Universidade Federal de Campina Grande - Unidade Acadêmica de Ciências Atmosféricas, UFCG, 2006.

CODEVASF. Plano de Controle Ambiental - PCA. Empreendimento: Projeto de Irrigação do Gorutuba. Brasília-DF, 2007.

DIJ - Distrito de Irrigação Jaíba: Disponível em http://www.abanorte.com.br/aabanorte/associoacoes-parceiras/dij-projeto-de-irrigacao-de-jaiba/: Acessado em 2013

FREITAS A. M.; PEREIRA, C.; COSTA, D. A. Geologia e Hidrogeologia de Jaíba, Verdelândia e Varzelândia, Norte de Minas Gerais. Trabalho de Conclusão de Curso (Bacharel em Geologia), Universidade Federal de Minas Gerais - MG, 2008. Disponível em: http://www.bibliotecadigital.ufmg.br

GOMES, H.F.B. Balanços de Radiação e Energia em Áreas de Cultivo de Cana-de açúcar e Cerrado no Estado de São Paulo Mediante Imagens Orbitais. Tese de Doutorado.

Universidade Federal de Campina Grande - PB, 2009.

HARISON, L. P. Fundamental concepts and definitions relating to humidity. In Wexler, A. (ed). Humidity and Moisture. V. 3. Reinhold Publishing Company. New York, EUA, 1963.

IBGE. Manual técnico de uso da terra. Manuais técnicos em geociências, Rio de Janeiro, 2006. ISSN 0103-9598. 91p.

Instituto Nacional de Meteorologia - INMET: Disponível em http://www.inmet.gov.br/portal/: Acessado em 2013

Instituto Nacional de Pesquisa Espacial - INPE: Disponível em http://www.inpe.br/: Acessado em 2013.

LIMA, E. P et al. Estudo da evapotranspiração real diária utilizando imagem de satélite na bacia do rio Paracatu. Anais II Seminário de Recursos Hídricos da Bacia Hidrográfica do Paraíba do Sul: Recuperação de Áreas Degradadas, Serviços Ambientais e Sustentabilidade, Taubaté, Brasil, 2009.

MOURA, A. R. Estimativa da Evapotranspiração de Referência em bacia experimental na região Nordeste. Dissertação de Mestrado em Engenharia Civil - Tecnologia Ambiental e Recursos Hídricos pela Universidade Federal de Pernambuco - UFPE, Recife - PE, 2009.

SILVA, B. B. da; LOPES, G. M.; AZEVEDO, P. V. Balanço de radiação em áreas irrigadas utilizando imagens Landsat 5 -TM. Revista Brasileira de Meteorologia, v.20, n.2, p.243$252,2005$. 
SILVA, B. B; BRAGA, A. C; BRAGA, C. C. Balanço de radiação no perímetro irrigado São Gonçalo PB mediante imagens orbitais. Revista Caatinga (UFERSA. Impresso), v. 24, p. 145-152, 2011.

REZENDE, J.F.R. Gestão de Informações utilizando a Tecnologia de

Geoprocessamentopara o Projeto Jaíba - Etapa II. Trabalho de conclusão de curso (Especialista em Geoprocessamento). Universidade Federal de Minas Gerais - MG, 2002.

TREZZA, R. Evapotranspiration from a remote sensing for water a management in an irrigation system in Venezuela. Interciencia, v. 31, n.6, p.417-423, 2006.

VELOSO, G.A. ROSA.R. Avaliação do Albedo de Superfície Utilizando Imagens do Satélite Landsat 5 - TM e o algoritmo SEBAL. Anais XVI Simpósio Brasileiro de Sensoriamento Remoto - SBSR, Foz do Iguaçu, p. 8098-8105, 2013.

VELOSO, G. A. Análise Espaço Temporal dos Componentes do Balanço de Radiação, Energia e Evapotranspiração, Usando Técnicas de Sensoriamento Remoto em Áreas Irrigadas do Projeto Jaíba/MG. Dissertação (Mestrado em Geografia) - Instituto de Geografia/IG, Universidade Federal de Uberlândia, Uberlândia, 2013. 


\section{Autores}

Gabriel Alves Veloso - Possui graduação Geografia pela Universidade Estadual de Montes Claros (UNIMONTES) e Mestrado em Geografia pela Universidade Federal de Uberlândia (UFU). Atualmente é professor na Universidade Federal do Pará (UFPA) e doutorando em Geografia pela Universidade Federal de Goiás (UFG), atuando no Laboratório de Processamento de Imagens e Geoprocessamento - LAPIG.

Manuel Eduardo Ferreira - Possui graduação em Geografia pela Universidade de Brasília (UnB), Mestrado em Processamento de Dados em Geologia e Análise Ambiental pela Universidade de Brasília (UnB) e doutorado em Ciências Ambientais pela Universidade Federal de Goiás (UFG), com estágio pós-doutorado no Woods Hole Research Center (Massachusetts, EUA). Atualmente é professor adjunto 4 da Universidade Federal de Goiás (UFG), atuando na área de Cartografia e Geoprocessamento, vinculado ao Instituto de Estudos Sócio-Ambientais (IESA), e ao Laboratório de Processamento de Imagens e Geoprocessamento - LAPIG.

Bernardo Barbosa da Silva - Possui Graduação em Meteorologia, Mestrado em Meteorologia e Doutorado em Engenharia Civil, todos cursados na Universidade Federal da Paraíba (UFPB). Atualmente é Professor da Universidade Federal de Campina Grande (UFCG), atuando no Programa de Pós-Graduação em Meteorologia, bolsista de produtividade CNPQ - nível 1C.

Artigo recebido em: 4 de Janeiro de 2017.

Artigo aceito em: 19 de janeiro de 2017. 